\title{
A mimese como ferramenta criativa em projetos bioinspirados
}

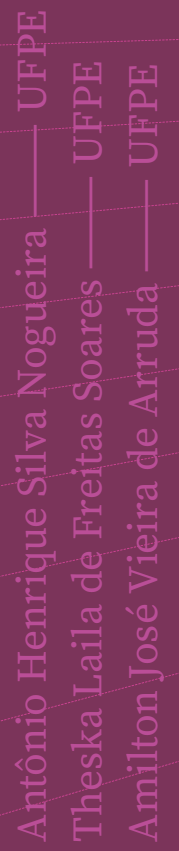




\section{INTRODUÇÃO}

Antes de aprofundar sobre o tema da mimese no design, é categórico considerar que esta investigação está inserida no campo dos métodos criativos, sendo assim, é importante analisar previamente alguns aspectos gerais sobre $o$ ato de conceber e perceber os artefatos, uma vez que, compreender a atividade projetual no design, enquanto processo de criação, significa: entender a capacidade humana de solucionar problemas, criar conceitos, fazer associações, distinções e desvios a partir de habilidades criativas inerentes à mente humana. À vista disso, é importante ressaltar que, substancialmente um artefato de design está interligado dialeticamente aos aspectos cognitivos atribuídos por um "sujeito criador" (BOMFIM, 1984), sendo este agente o designer; da 
mesma maneira que tal objeto será percebido através da ótica do "sujeito consumidor" (BOMFIM, 1984), também denominado: receptor ou usuário.

Além disso, é importante complementar que esse processo de fruição perceptiva ocorre sob um filtro que contempla aspectos simbólicos, crenças e valores estabelecidos no imaginário coletivo, no qual os agentes citados estão inseridos em diversas camadas de contexto, uns mais específicos e outros mais amplos, identificados a partir do macro conjunto de indivíduos: a sociedade.

Deste modo, em síntese, é importante enfatizar que a atividade projetual do design está intrinsecamente associado à criatividade, logo, simultaneamente está associada à cognição e permeia o filtro do contexto social.
Figura 1.

Fruição perceptiva do artefato (objeto mimeticamente projetado - OMP). Fonte: Elaborados pelos autores.

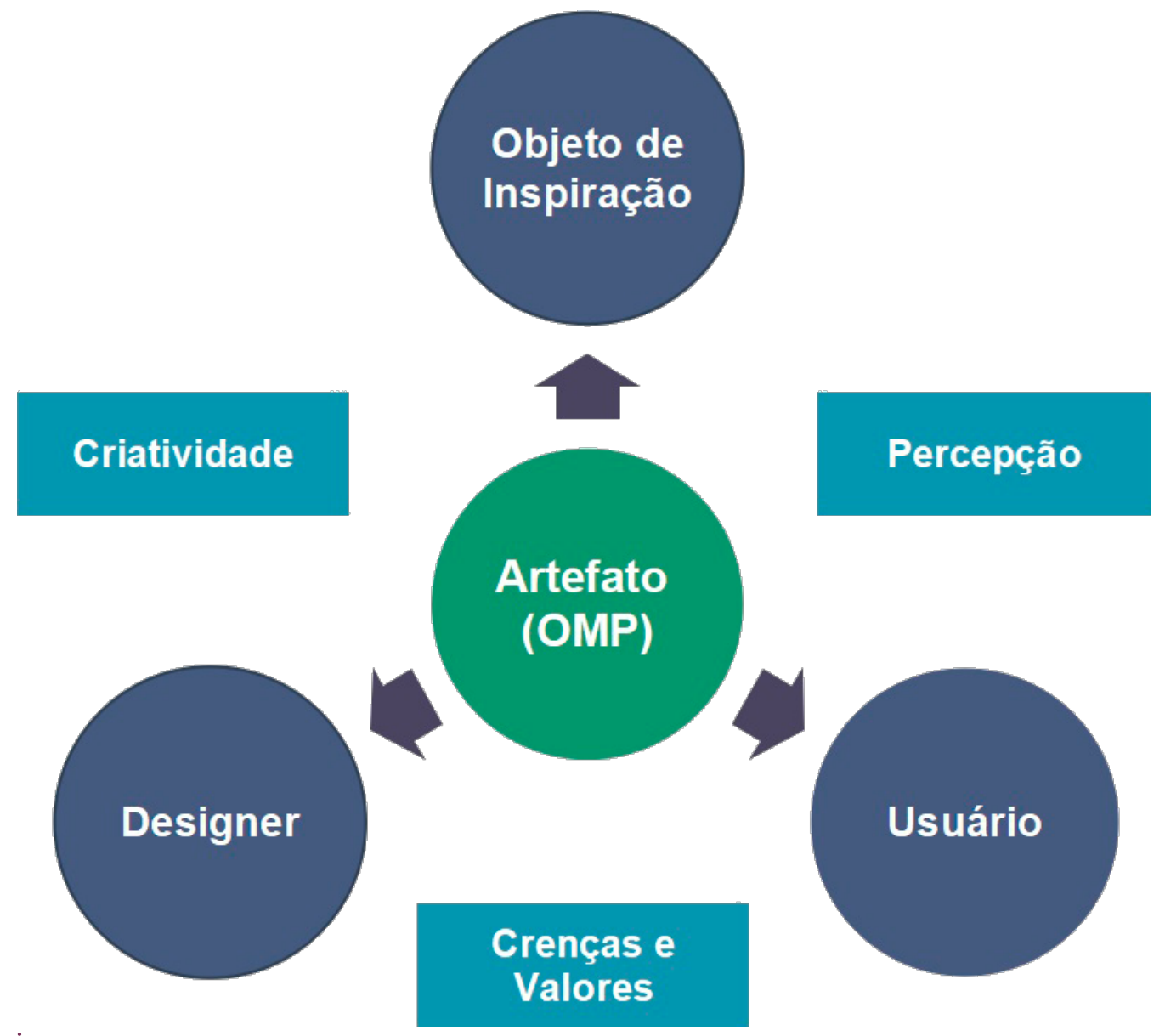

fronteiras do design. [entre] outros possíveis 
Reforçando a discussão sobre os temas tratados, e atribuindo um caráter multidisciplinar para tal, Souza (2001) elucida a questão da criatividade através da ótica das ciências sociais, psicológicas e cognitivas, e dentre as diversas definições de criatividade extraídas em sua dissertação vale destacar duas afirmações: 1 - A que considera a criatividade como o ato no qual "se manipula símbolos ou objetos externos para produzir um evento incomum para si ou para o meio" e 2 - A afirmação de Alencar (1993) que define criatividade como sendo "a emergência de algo único e original". Logo, resumidamente, a criatividade possui caráter de originalidade e/ou inovação a partir da reconfiguração de "símbolos" ou "objetos externos".

Dito isto, é preciso aprofundar na relação entre o usuário e os objetos de design, para que se tenha condições de avaliar o processo de concepção dos artefatos e discorrer sobre qual é o objetivo e quais são as necessidades que determinado produto industrial irá satisfazer. Para elucidar sobre esta questão, Lobach (2001) afirma que essencialmente os aspectos mais importantes dessa relação são as "funções do produtos", e que elas são perceptíveis na própria utilização do artefato, cada produto possui uma função primordial e outras secundárias mas de maneira geral existem 3 categorias de funções: 1 - prática, 2 - estética e 3 - simbólica.

De acordo com Lobach (2001) a "função prática" diz respeito aos "aspectos fisiológicos do uso", por exemplo, uma cadeira tem a função de fazer o usuário descansar através do ato de sentar-se. A "função estética" contempla "um aspecto psicológico da percepção sensorial durante o uso" (LOBACH, 2001), essa percepção depende das experiências anteriores do usuário com as características estéticas (forma, cor, superfície, som etc.) e da consciência dessas caraterísticas. Portanto, de acordo com autor, a aparência estética é percebida pela totalidade e se dá através da aparência material do produto e sua configuração; assim, seria o principal motivo de escolha de um modelo de automóvel em relação a um outro qualquer com a mesma função prática, preço e especificações por exemplo: o usuário escolhe o produto a partir da percepção multissensorial sobre a configuração estética.

E por fim, a "função simbólica" que refere-se a "todos os aspectos espirituais, psíquicos e sociais do uso" (LOBACH, 2001); ou seja, 
quando o usuário estabelece uma relação de percepção com o produto a partir das suas experiências anteriores através de uma associação de ideias. Lobach (2001) afirma que "um símbolo é um sinal, um signo que existe para algo"; sendo assim, conclui-se que a função simbólica se estabelece através da relação de uma coisa à outra por meio da experiência adquirida.

A partir dessas premissas, pode-se então sugerir uma reflexão preliminar sobre o processo criativo no design, pois já foi definido que se trata de uma abordagem cognitiva, que está inserida em um contexto social e que possui caráter original ou inovador. Já a partir dos conceitos de criatividade citados, se conclui sintaticamente que o design, enquanto método criativo, trata da "manipulação de símbolos para a produção de algo único e original" (síntese dos conceitos de criatividade citados).

Sendo assim, pode-se dizer que relevante parcela dos objetos mimeticamente projetados (OMP) bastante originais são os chamados projetos bioinspirados. Neste contexto, ressalta-se a Biônica e Biomimética, termos difundidos por Benyus (1997) como uma ciência que estuda os modelos da natureza e depois imita-os, inspira-se neles ou em seus processos para resolver problemas humanos. Estas soluções são embasadas numa perspectiva da natureza como modelo, medida e mentora, cujos princípios são descritos a seguir: 
"A natureza como modelo: Inspiração e mimese nas soluções da natureza para aplicações práticas;

" A natureza como medida: Usa o padrão ecológico como parâmetro para as inovações. Após 3,8 bilhões de anos de evolução, a natureza aprendeu aquilo que funciona, é mais apropriado, econômico e durável;

"A natureza como mentora: Representa uma nova forma de ver e valorizar a natureza, inaugura uma era cujas bases se sustentam, não naquilo que se pode extrair dela, mas no que se pode aprender com ela.

Apesar de derivar da palavra grega "Biomimesis", em que "bios" significa vida e "mimesis", imitação, não se restringe apenas a uma imitação da forma biológica, mas considera também o conceito de replicação do comportamento dos organismos biológicos através de um olhar atento às soluções da natureza. Existe uma infinidade de bons exemplos de eco eficiência, através de organismos que se constroem e se sustentam com o mínimo de desperdício de materiais e energia, e que ainda coexistem em harmonia com a biosfera. Evidenciar esta nova forma de perceber a natureza, é bem diferente da ideia de exploração a que geralmente o homem a tem associado.

Portanto, observando como a natureza opera na criação das suas 
espécies, sejam vegetais, animais ou minerais, pode-se transpor este mesmo método no desenvolvimento de produtos, sistemas, construções e até mesmo serviços, pois os "critérios" observados nos seres vivos mais adaptados, podem servir de base para o desenvolvimento de soluções mais eficientes. (BENYUS, 1997)

\section{MIMESE NO DESIGN}

O conceito de mimese é bastante abrangente, e engloba diversas áreas do conhecimento bem distintas entre si; é possível encontrar aplicações do termo na filosofia, na sociologia e até mesmo no direito, é muito comum, portanto, a utilização nas artes visuais e na arquitetura. Como exemplo dessa diversidade de aplicações, podemos citar a influência da biônica nas áreas projetuais (design, arquitetura e engenharia), quando um projeto traz referências a padrões e estruturas encontrados na natureza. Na informática também são encontradas diversas analogias, principalmente no design das interfaces, no que diz respeito às interações entre dispositivos e usuários. Por exemplo, todos estão bastante familiarizados a guardar arquivos pessoais digitais em pastas organizadas em uma área de trabalho semelhante a elementos encontrados em um escritório real. Mesmo quando se exclui um arquivo que vai parar numa lixeira etc. Na robótica a forma humanóide é também uma imitação das formas humanas. Por exemplo: desenhos, pinturas, esculturas e até mesmo os jogos 
eletrônicos, estão repletos de referências do mundo natural traduzido para o artificial.

No dicionário Michaelis, o termo Mimese significa a imitação ou a representação da realidade. Além deste termo é possível encontrar outras definições correlatas; são elas:

Analogia: Semelhança de propriedades entre coisas ou fatos. Metáfora: Figura de linguagem em que uma palavra que denota um tipo de objeto ou ação é usada em lugar de outra, de modo a sugerir uma semelhança ou analogia entre elas; translação (por metáfora se diz que uma pessoa bela e delicada é uma flor, que uma cor capaz de gerar impressões fortes é quente, ou que algo capaz de abrir caminhos é a chave do problema); símbolo.

(DICIONÁRIO MICHAELIS, 2020)

Analisando o significado das três palavras, conclui-se que a semântica comum aos termos diz respeito à relação que uma coisa faz à outra, por imitação ou semelhança. 


\section{OBJETOS MIMETICAMENTE PROJETADOS}

Essencialmente, o que define um artefato como um objeto mimeticamente projetado (OMP) é a referência estética e simbólica que ele faz a outro artefato, estrutura ou signo, no qual esse elemento de origem possui suas próprias "funções" (LOBACH, 2001) e suas próprias "propriedades estéticas relevantes" (NANAY, 2016), com conteúdo semântico e aspectos perceptuais já consolidados consensualmente. Sendo assim, percebe-se uma relação de maior complexidade na percepção do OMP, pois além de transmitir as informações inerentes aos elementos configurativos dele próprio, também se faz presente elementos estéticos e simbólicos pré-existentes oriundos do objeto de inspiração original que foi utilizado como referência.

Desse modo, cria-se uma relação semiótica, na qual o OMP se torna uma representação do objeto original - sua principal fonte de inspiração, entretanto, com contexto e significação próprios. Esse grau de parentesco agrega valores estéticos ao objeto.

\section{TIPOS DE MIMESE}

A princípio, todo signo tem potencial para ser mimetizado; todavia, faz-se coerente que a escolha deste elemento simbólico seja baseada na sua relevância estética, no que diz respeito à sua percepção ampla, ou à totalidade enquanto "figura" (LOBACH, 2001), na densidade significativa e principalmente no reconhecimento do usuário sobre o conteúdo semântico que será atribuído ao objeto mimeticamente projetado. De modo geral, os objetos miméticos podem ser divididos em dois grandes grupos:

01. Objetos inspirados em símbolos culturais diversos: artes visuais, artesanato, arquitetura etc.;

02. Objetos inspirados em elementos naturais, oriundos da biomimética. 
A seguir, alguns exemplos de OMP do primeiro grupo, influenciados por outros símbolos culturais nas áreas das artes visuais, artesanato e na história do Brasil:

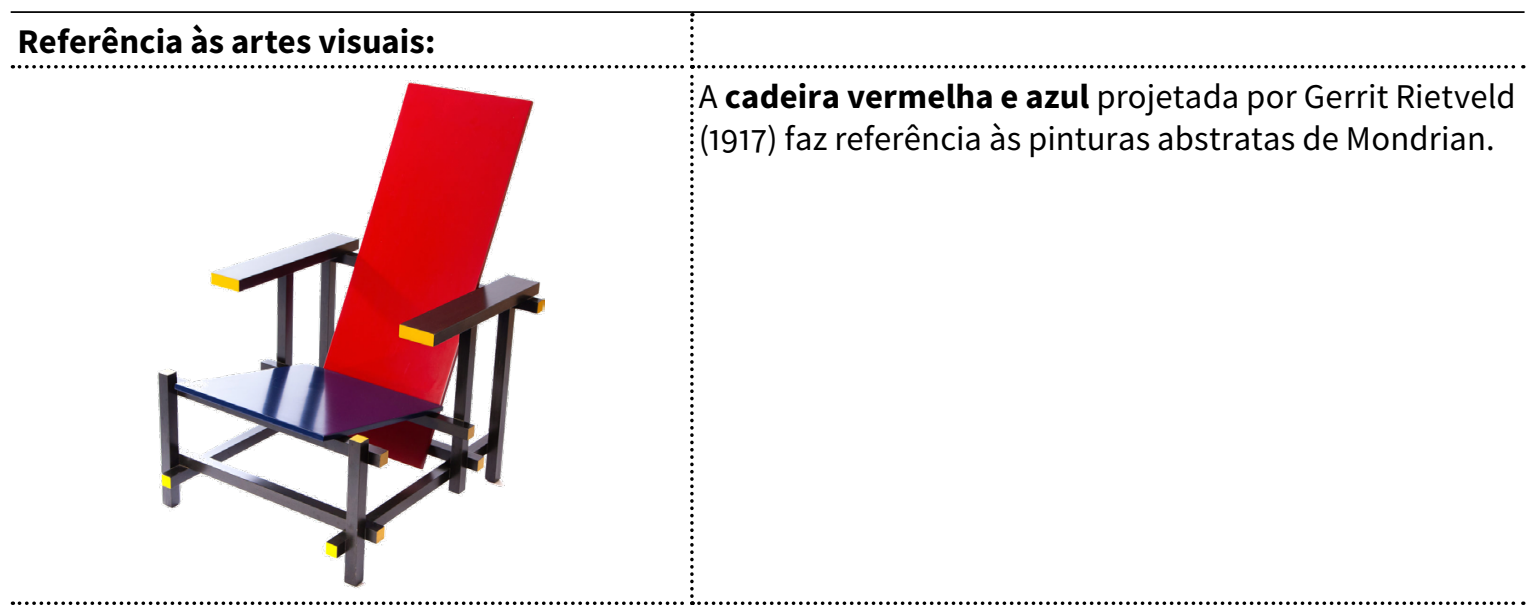

Figura 2. Cadeira Vermelha e Azul (Gerrit Rietveld, 1917)

\section{Referência ao artesanato:}

A cadeira vermelha projetada pelos irmãos Campana, umas das obras mais icônicas da dupla, de acordo com (FERNANDES, 2016, pág 20) um perfeito exemplar de "uso intencional de características artesanais em produtos do design contemporâneo em contraste com elementos industriais".

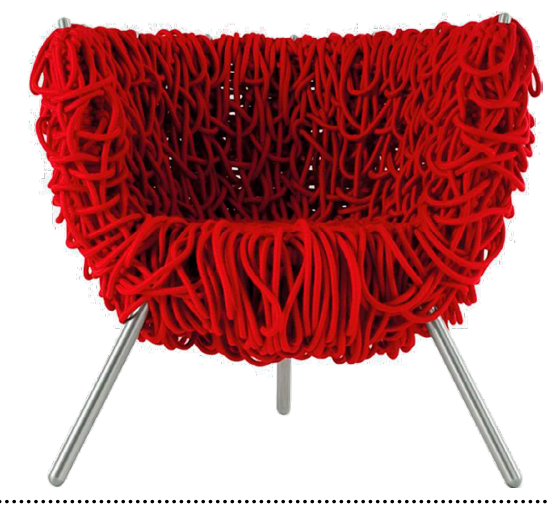

Figura 3. Cadeira Vermelha (Irmãos Campana, 1992)

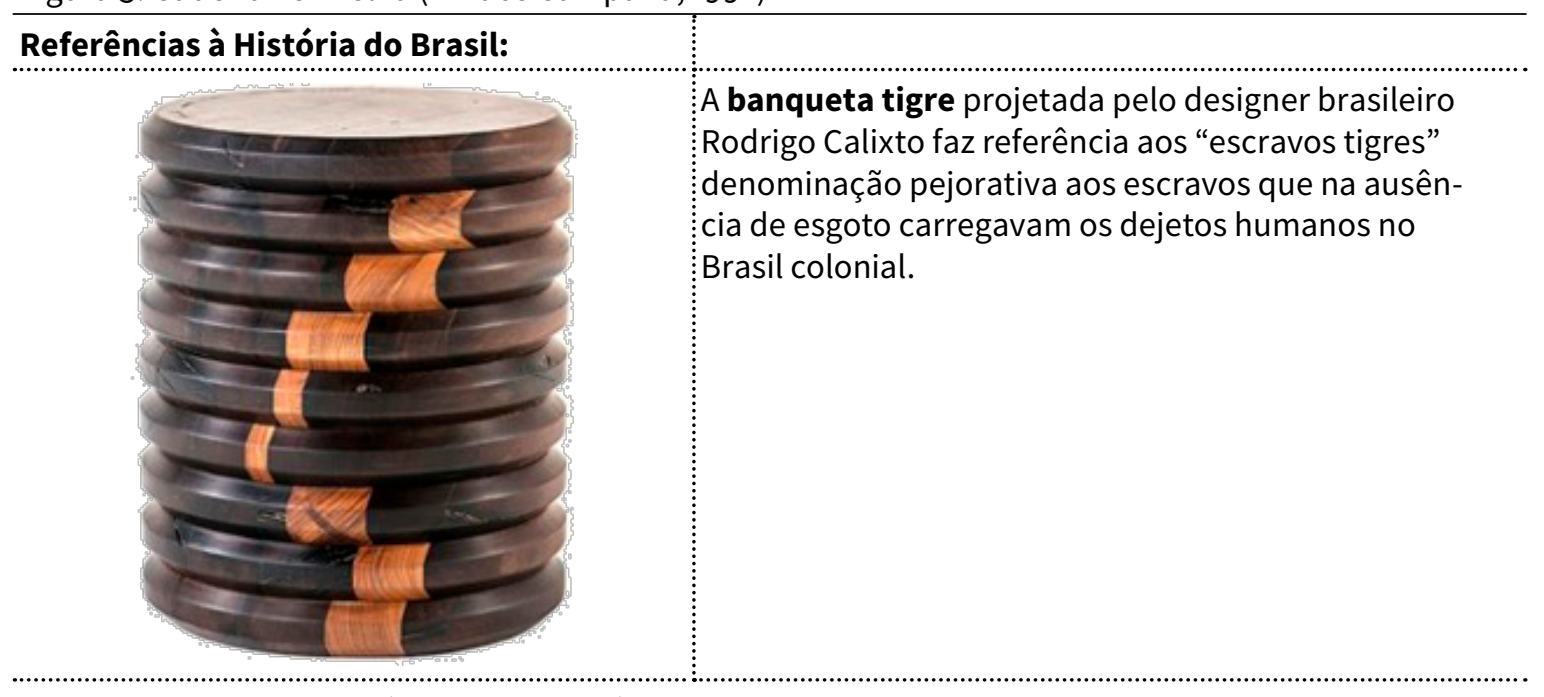




\section{ANALOGIA}

$\mathrm{Na}$ antiguidade clássica, a analogia era abordada pelos filósofos Aristóteles e Platão como uma abstração compartilhada na qual objetos análogos comungam em algum sentido, seja uma ideia, um padrão, uma regularidade, um atributo ou uma função.

Como método, a analogia assume um caráter capaz de vencer problemas através de um raciocínio lógico, assim como ajuda na tomada de decisões, nos diferentes campos da criação, percepção e criatividade. Da sua aplicação resulta um amplo conjunto de soluções para diferentes áreas em conformidade com o interesse e conteúdo de cada ciência.

Sendo muito utilizada pela Biônica e a Biomimética, as técnicas de analogia se revelam muito úteis para se descobrir novos princípios, formas, processos, estruturas etc.; contribuindo nas dinâmicas de interpretação das estruturas naturais. Ao longo da história, este é o método mais comum para encontrar soluções de concepção com referência no mundo natural.

A seguir, alguns tipos de Analogias classificadas por Arruda (2002):

" Analogia Orgânica: Busca encontrar o equilíbrio entre os organismos humanos, as obras de arte e os sistemas mecânicos. (STEADMAN, 1988)

" Analogia Classificatória: Observa os métodos estabelecidos da botânica e zoologia para aplicação na Arquitetura e no Design. (STEADMAN, 1988)

" Analogia Anatômica: Traz uma sistemática de trabalho que estuda a estrutura do esqueleto animal comparando-os com as construções da engenharia. (STEADMAN, 1988)

》Analogia Darwiniana: Busca explicar que os objetos e as construções são feitos através de cópias repetidas através dos tempos, como acontece com a evolução natural. (STEADMAN, 1988)

"Analogia Sensorial: Estuda sistemas de controle e transmissão de informação de organismos vivos para transpô-los em modelos eletrônicos e mecânicos, com objetivo de reduzir e otimizar ao máximo seus resultados. (ARRUDA, 2002) 
A seguir, serão apresentados de maneira mais detalhada três tipos básicos de Analogia: morfológica, funcional e simbólica, que sintetizam melhor o método relacionado com a Biomimética, segundo Soares (2016).

\section{ANALOGIA MORFOLÓGICA}

Bonsiepe (1978) define a analogia morfológica como a busca experimental de modelos elaborados a partir da tradução de características estruturais e formais para transpor-lhe em projetos. Sendo assim, este tipo de analogia procura estudar e analisar o porquê da forma natural, as inter-relações da sua geometria, observando e compreendendo suas texturas, atentando para as características do shape (forma externa), das partes e componentes, dos detalhes de alguma parte ao nível macro ou microscópico, assim como, para as suas formas estruturais.

A análise de fenômenos morfológicos da natureza facilita e estimula a capacidade de percepção de detalhes e princípios presentes em sua estrutura. Ideias inovadoras vêm surgindo de pesquisas sobre sistemas e propriedades naturais que nem sempre se traduzem apenas na estética, na qual a forma natural favorece também o ganho em eficiência. Neste sentido, Versos (2010) traz um bom exemplo de analogia morfológica com o Trem-bala Shinkansen desenvolvido pelo engenheiro Eiji Nakatsu (Figura 5).

Figura 5.

SHINKANSEN (Japão), trem-bala de alta velocidade mais rápido do mundo, redesenhado tendo como base o bico de um Martim-Pescador. Fonte: SOARES, 2016 apud
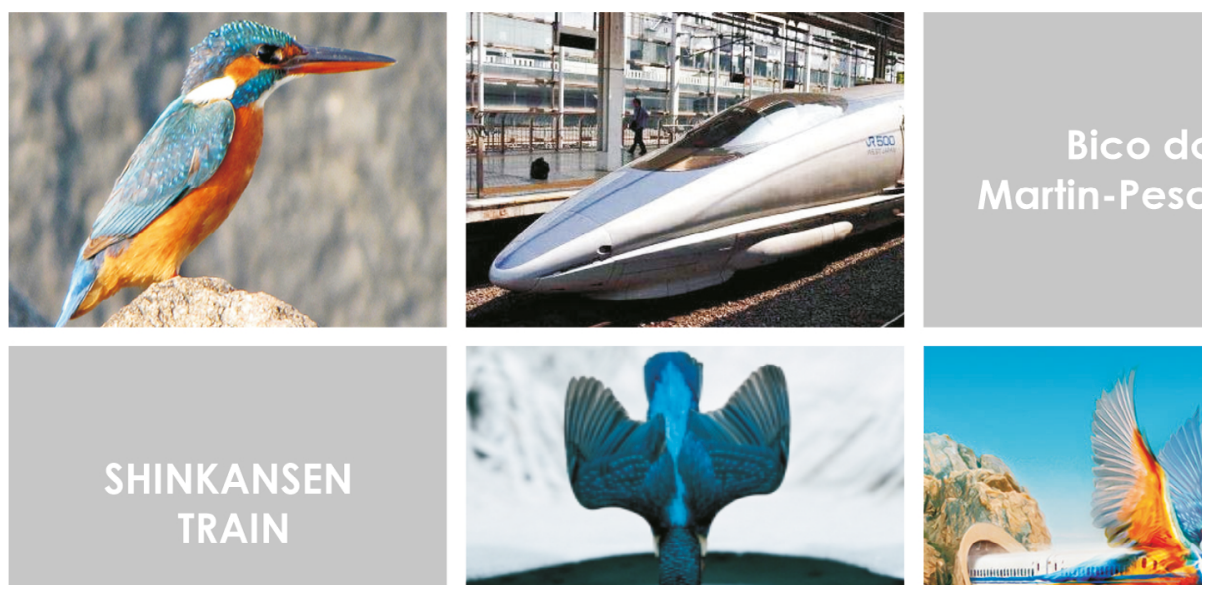
O projeto tem como referência a forma do bico alongado do pássaro Martim-Pescador, que facilita o mergulho sem espirrar água em busca de sua refeição. Visando solucionar um dos grandes problemas do trem bala, que reside na vibração e o barulho, o engenheiro buscou inspiração no formato do bico deste pássaro, o que resultou numa melhora significativa, tornando o veículo $10 \%$ mais rápido, consumindo $15 \%$ menos energia, $\mathrm{e}$ ainda, reduzindo a pressão do ar em 30\% em relação ao modelo anterior.

Sendo assim, a analogia morfológica comprova a eficiência das formas naturais, pois muitas delas se traduzem em ganhos além da estética, ou seja, também em performance. A Figura 6 apresenta mais alguns exemplos desse tipo de analogia.
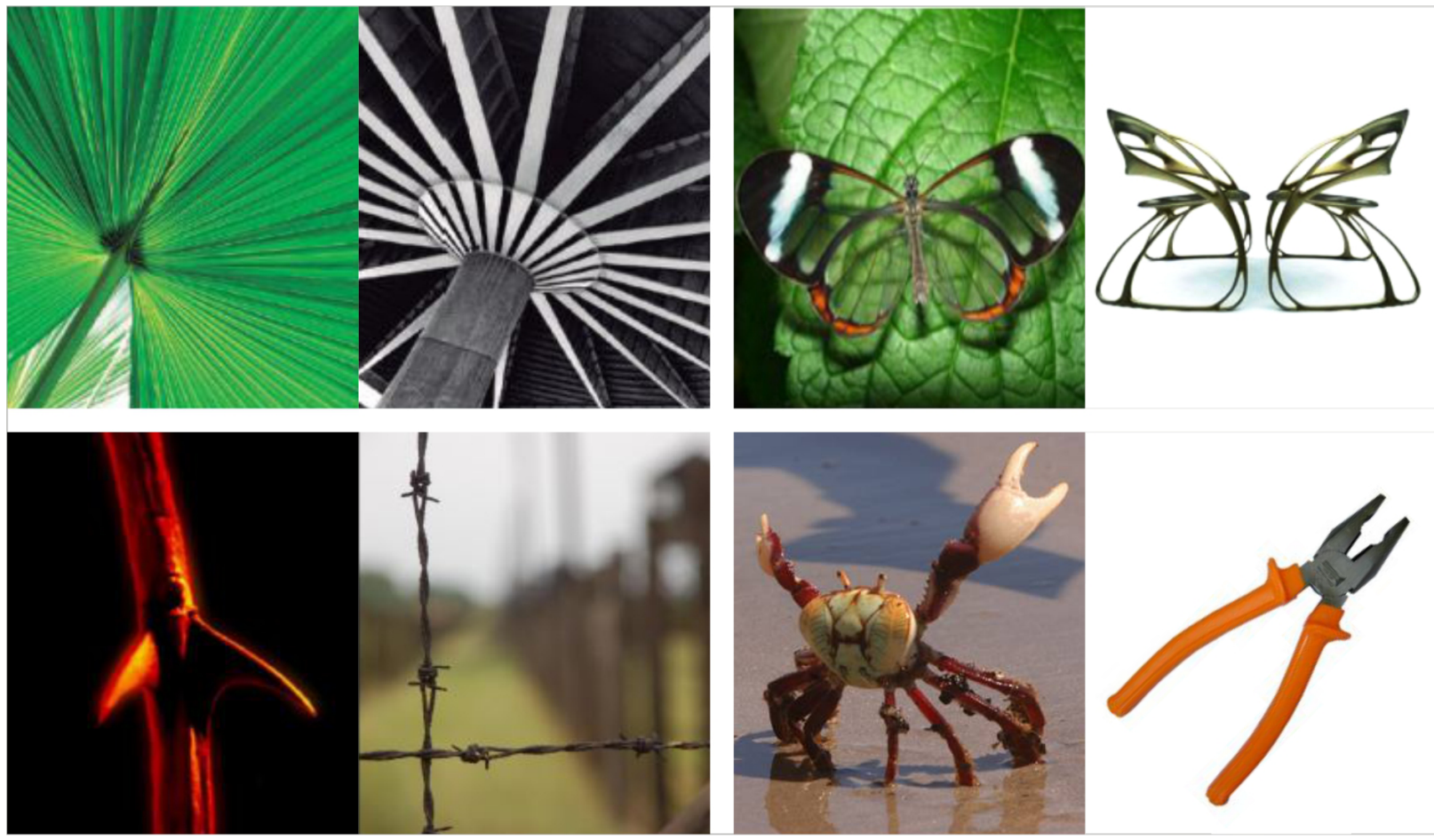

Figura 6.

Exemplos de Analogia

Morfológica - Coluna

estrutural/Folha da

palmeira leque; Cadeira/

Forma estrutural da bor-

boleta; Arame farpado/

Espinhos e Alicate/Pinça

do caranguejo. Fonte:

SOARES, 2016, p.34. 


\section{ANALOGIA FUNCIONAL}

De acordo com Soares (2016), este outro tipo de Analogia procura estudar sobre o funcionamento do sistema físico e mecânico natural; tenta compreender quais as funções que desempenham, tanto no todo quanto em suas partes e componentes. Em outras palavras, são evidenciados os atributos funcionais, qualidades específicas (não morfológicas) que se podem mimetizar da estrutura natural analisada. Uma vez que os organismos naturais desenvolveram habilidades complexas e altamente adaptáveis, pode-se mimetizar essas aptidões funcionais e aplicá-las em artefatos artificiais. Enquanto morfologicamente as analogias são limitadas, funcionalmente podem ser múltiplas.

A vantagem desta analogia é que, identificando-se estratégias e funções em objetos naturais, estas podem ser aplicadas em mais de um tipo de artefato, servindo para diversas soluções, como o caso do estudo das folhas de lótus, no qual o pesquisador Barthlott, 
identificou as funções de repelir a água e de autolimpeza de suas superfícies. Isso acontece devido ao ângulo formado pelas suas micro e nanoestruturas cerosas, que impedem o contato com a água, fazendo-a rolar e formar gotas que vão recolhendo a sujeira pelo caminho. Com isto, identificou-se que superfícies ásperas em nanoescala são mais hidrofóbicas que superfícies mais lisas. $\mathrm{Na}$ folha de lótus, a área de contato real é de apenas 2-3\% da superfície das gotas.

Essa analogia funcional foi aplicada comercialmente em produtos como a tinta Lotusan (Figura 7) e em outros materiais e produtos, tais como os têxteis, a madeira ou o vidro, através de sprays (BASF Lotus Spray) que simulam o mesmo efeito da planta. Na tinta, ao criar micro saliências, ela repele a água se auto limpando e resistindo a manchas durante décadas. Apesar de se replicar essas microestruturas, os artefatos gerados não se referem à forma das folhas em si e sim à função identificada de hidrofobia e autolimpeza.
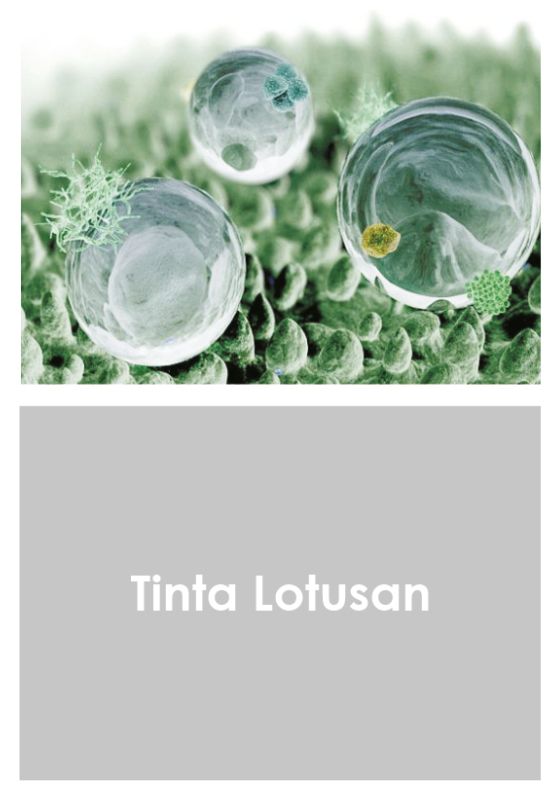
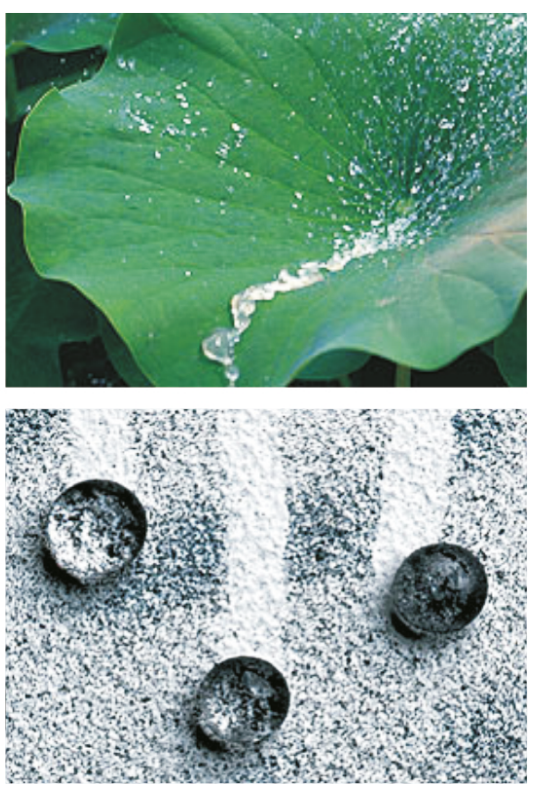

Figura 7.

LOTUSAN (Alemanha), tinta que repele a água e resiste a manchas durante décadas, inspirada nas microestruturas das folhas de lótus. Fonte: SOARES, 2016 apud VERSOS, 2010, p.36.

\section{Folha de Lótus}

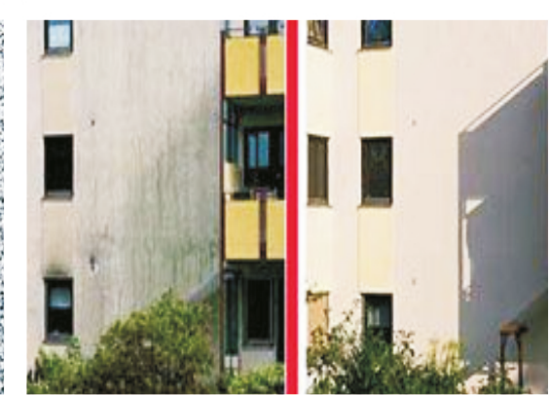




\section{ANALOGIA SIMBÓLICA (SEMÂNTICA)}

$\mathrm{Na}$ analogia simbólica estão os casos de imitação mais abstratos que não correspondem à fidelidade das formas nem necessariamente das funções. Sendo assim, os artefatos produzidos possuem correspondência com aspectos da estrutura natural analisada com certo grau de abstração inerente das interpretações individuais de quem cria.

Expressivos exemplos de Analogia Simbólica são as excêntricas e orgânicas construções do espanhol Antoni Gaudí, com predominância pela arquitetura biomórfica, cheia de curvas e contracurvas, cujos elementos da natureza são desenhados em vários detalhes. Experimentando formas e materiais novos, o arquiteto se dedicava à cada esquina e à cada pormenor de suas criações buscando uma organicidade, o que acabou por caracterizá-lo.

Sua atitude naturalista, foi previamente abordada por D'Arcy Thompson (1961) relembrando sobre a emblemática obra da igreja da Sagrada Família em Barcelona. Segundo Pereira (2013), Gaudí confere torções parabólicas à fachada, fazendo uso de hipérboles e espirais em várias partes da construção, preenchendo a obra de motivos vegetais destacando a sua atitude naturalista e orgânica, num contrassenso à arquitetura gótica da época, em que para ele, as linhas retas não refletiam as leis da natureza com suas formas curvas. Cruz (2012) também reforça o "espírito natural" de Gaudí, que sempre foi interpretado numa atmosfera romântica e orgânica através da disposição das folhas, caules, raízes das plantas, e também nas pétalas das flores nesta obra, das quais as particularidades remetem para uma floresta ou mundo subaquático, apresentando, no interior, um aspecto panorâmico de bosque encantado, em que os jogos de luzes e os estreitos pilares intensificam essa atmosfera. As torres principais visíveis na fachada são inspiradas pela planta Sedum Sediforme, sendo pontuadas por pináculos ou flores. (Figura 8)

As formas naturais, como as espirais ou helicóides presentes nos caracóis ou búzios são abundantes em suas obras. Esse crescimento exponencial presente em tantos exemplos naturais revela-se como uma variante obsessiva no seu trabalho, através das torres, colunas, pináculos ou escadarias em caracol, dentre outros elementos. Como ele próprio afirmou, "Tudo sai do grande livro da Natureza, onde elementos como esta árvore junto ao meu ateliê é o meu mestre". (CRUZ, 2012) 

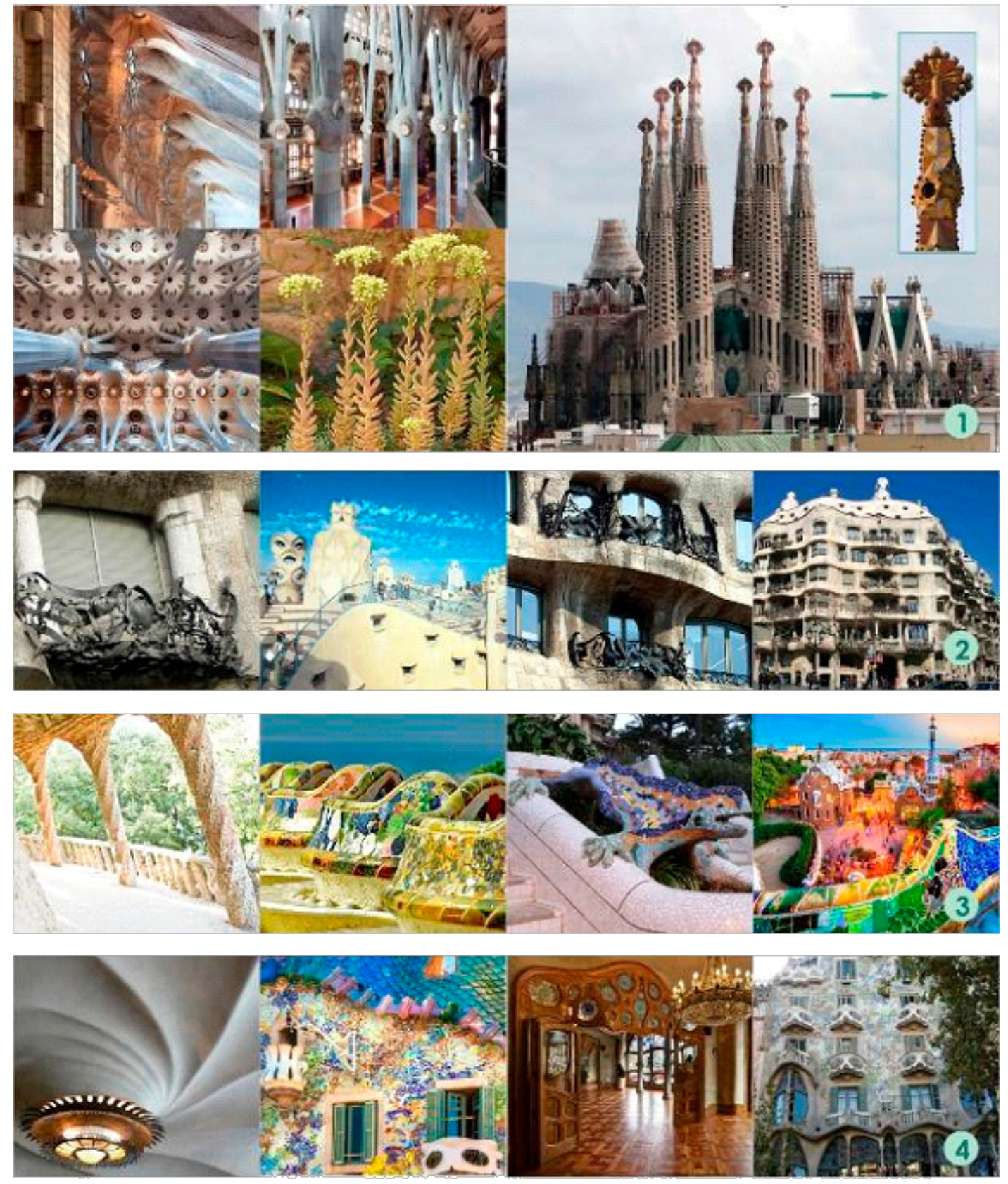
1- Igreja Sagrada Familia
2. La Pedrera
3- Parque Güell
4- Casa Batlló

Figura 8.

Exemplo de analogia simbólica na igreja Sagrada Família de Antoni Gaudì. Fonte: SOARES, 2016, p.42. 


\section{PROJETOS BIOINSPIRADOS NA UFPE}

Para Arruda (2002), a realização de projetos bioinspirados possui caráter sistemático que utiliza a analogia para traduzir os princípios encontrados na natureza, os quais poderão ser aplicados posteriormente à solução de um problema projetual. $O$ autor cita que a configuração de um objeto, vivo ou não, pode ser de alguma forma descrita; e apresenta algumas técnicas para essa descrição e compreensão da forma através dos seguintes passos: representação fotográfica, descrição verbal, esquematização (desenhos) e modelos. (Figura 9)

» Representação Fotográfica: Esta técnica revela uma riqueza de detalhes, que torna incontestável o alto nível de fidelidade de descrição de qualquer estrutura. Hoje há diversos meios de utilização desta técnica, seja por fotografias digitais com câmeras de altas resoluções ou até, em análises mais acadêmicas e menos criteriosas, através de câmeras de celular. Há ainda as que se utilizam de uma série de fontes de luz, tais como raio-X, ultravioleta ou infravermelhos. Há também métodos mais avançados de microscopia eletrônica e de varredura, que cada vez mais proporcionam descobertas de características morfológicas que revelam detalhes de estruturas internas dos elementos naturais a níveis cada vez menores, como o recente microscópio que usa feixe de elétrons no Japão, capaz de obter imagens ao nível atômico. Através da capacidade de ampliações de imagens e das fotografias digitais com seus softwares de computadores mais velozes, se têm revelado e facilitado o entendimento e a descrição pormenorizada de estruturas. Para o estudo, deve-se tirar as fotografias, ou consegui-las através de outros meios (internet), servindo para revelar o todo, secções, detalhes, partes, componentes, e demais aspectos do elemento analisado, que sejam do interesse do pesquisador; Descrição Verbal: Em seguida, procura-se investigar informações referentes ao elemento especificamente analisado, sejam detalhes técnicos, científicos (taxonomia, etc.) ou históricos curiosos, assim como descrever os detalhes 
observados nas fotografias, até que se possa resumir e extrair as características essenciais da forma estudada. Pressupõe-se que a pesquisa sobre o contexto da estrutura natural deve colaborar para um entendimento da forma (morfologia) com mais níveis de referências, resultando em maiores possibilidades criativas de representações; e ainda, representações mais coerentes. Descrever o contexto de uma dada estrutura natural e o que se observa dela em seu ambiente real e dinâmico, amplia a qualidade dos dados, pois permite verificar aspectos como ciclo de vida, movimentos, materiais, crescimento, variação de cores e tamanhos, funções, interações com outros elementos, organismos ou componentes etc. Nem sempre é possível colher esses dados por imersão, mas a experiência traz mais e melhores resultados.

"Esquematização: Através de desenhos que podem se apresentar como descrições mais fidedignas dos elementos reais estudados (desenhos de observação) e, posteriormente, como sínteses ou abstrações geométricas destes. Tais esquemas também podem se ater a destacar características ou princípios específicos desses elementos, enfatizando detalhes ou outro aspecto qualquer de interesse do pesquisador que tenha coerência com a origem do elemento analisado;

" Modelo: O processo se encerra com a execução de um modelo tridimensional que sintetiza o esquema realizado. 
Figura 9.

Esquema do método

utilizado pelo profes-

sor Amilton Arruda.

Fonte: SOARES,

2016 apud ARRUDA,

2002, p.92.

Pode ser feito de qualquer material, dependendo da função e intenção desejada e, para tanto, há necessidade de conhecimento prévio de técnicas de modelagem. Como a utilização de softwares que ampliam e facilitam a visualização do modelo, estes também podem ser feitos de maneira virtual, além do modelo físico.

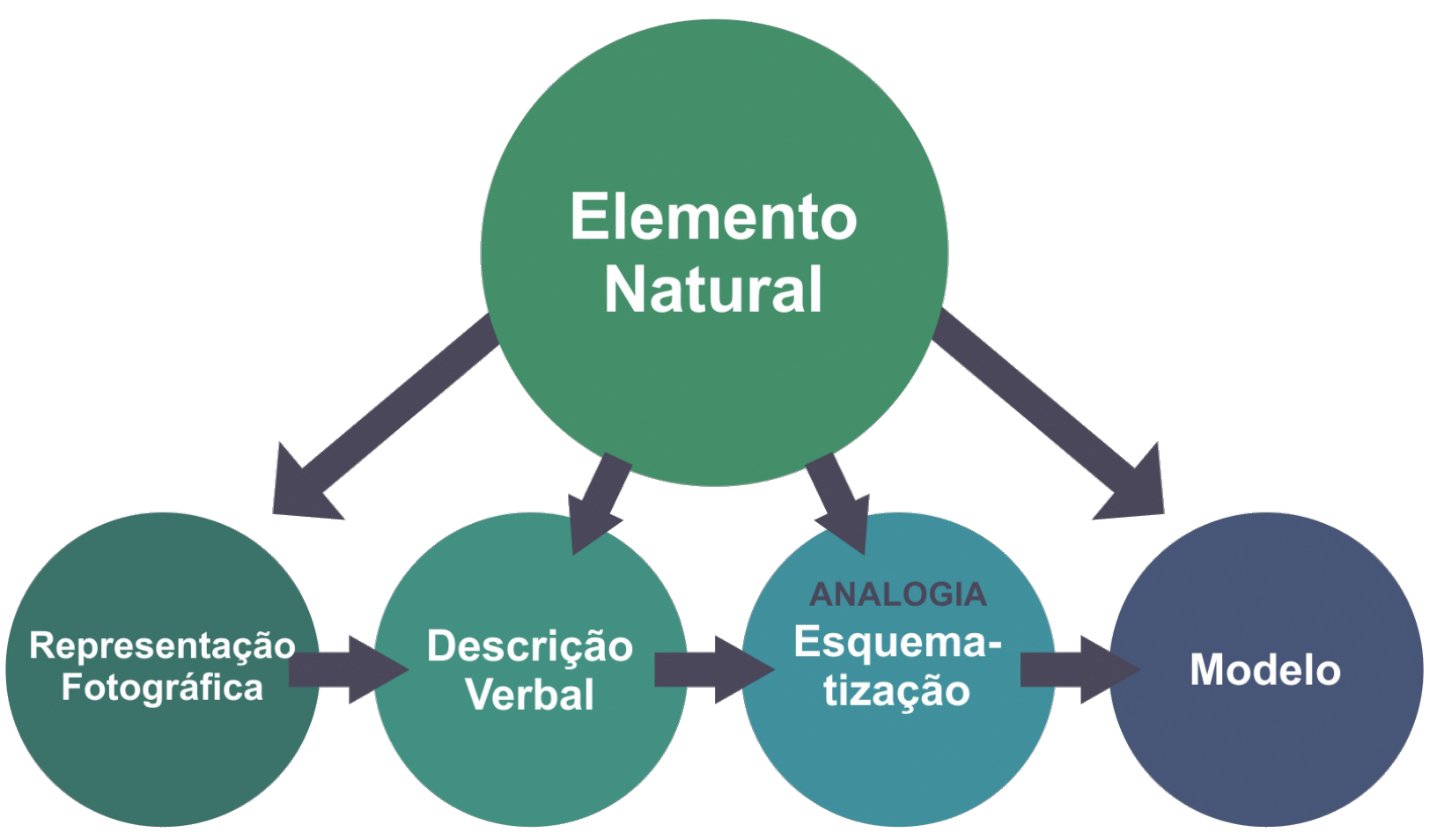


Um exemplo da aplicação deste método em termos acadêmicos é o Estudo da Alpínia esquematizado na Figura 10. 0 modelo em questão levou em consideração o formato côncavo das pétalas da flor da planta e sugere aplicação como peça modular para iluminação pública.
Figura 10.

Estudo da Alpínia por Higor Viana e Jean

Carlo em formato de banner. Fonte: SOARES, 2016, p.97.

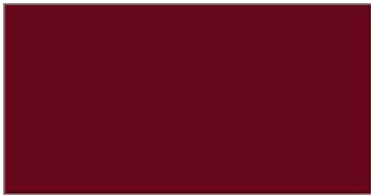

Alpínia
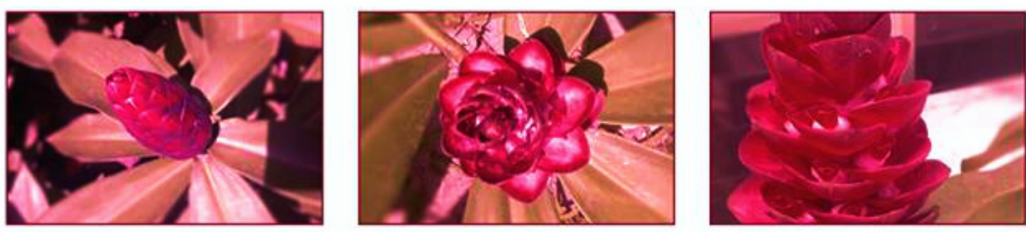

Alpinia é um genera botánico da fonlili Zing beraceoce, de origem asidtica. É populamente conhecido como vindecod. Nomeado por lineu em homenogem oo botanico italiano Prospero Alpini (1553-1617). De porte mécia, a olphio é uma planta que combina muito bem com paisogens tropicais Compreende cerca de 400 especies produz intorescéncias belissimas con fiores pequenas de coloroçoo bronca e brocteas vemehnas a roseas As tathas soo amamentais tamberm Muito ústica esta planta tamberm e utilizada conto flor de conte. Deve ser cultivoda a pleno sol ou meia sombra. Mutiplica-se por mudas au por divisá das touceiras Hizamos para estuda, esta especie que e uno variante

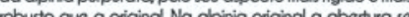
chis a

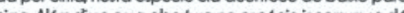

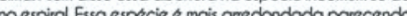
unm concha e maicr em comparaḉóo com outras.
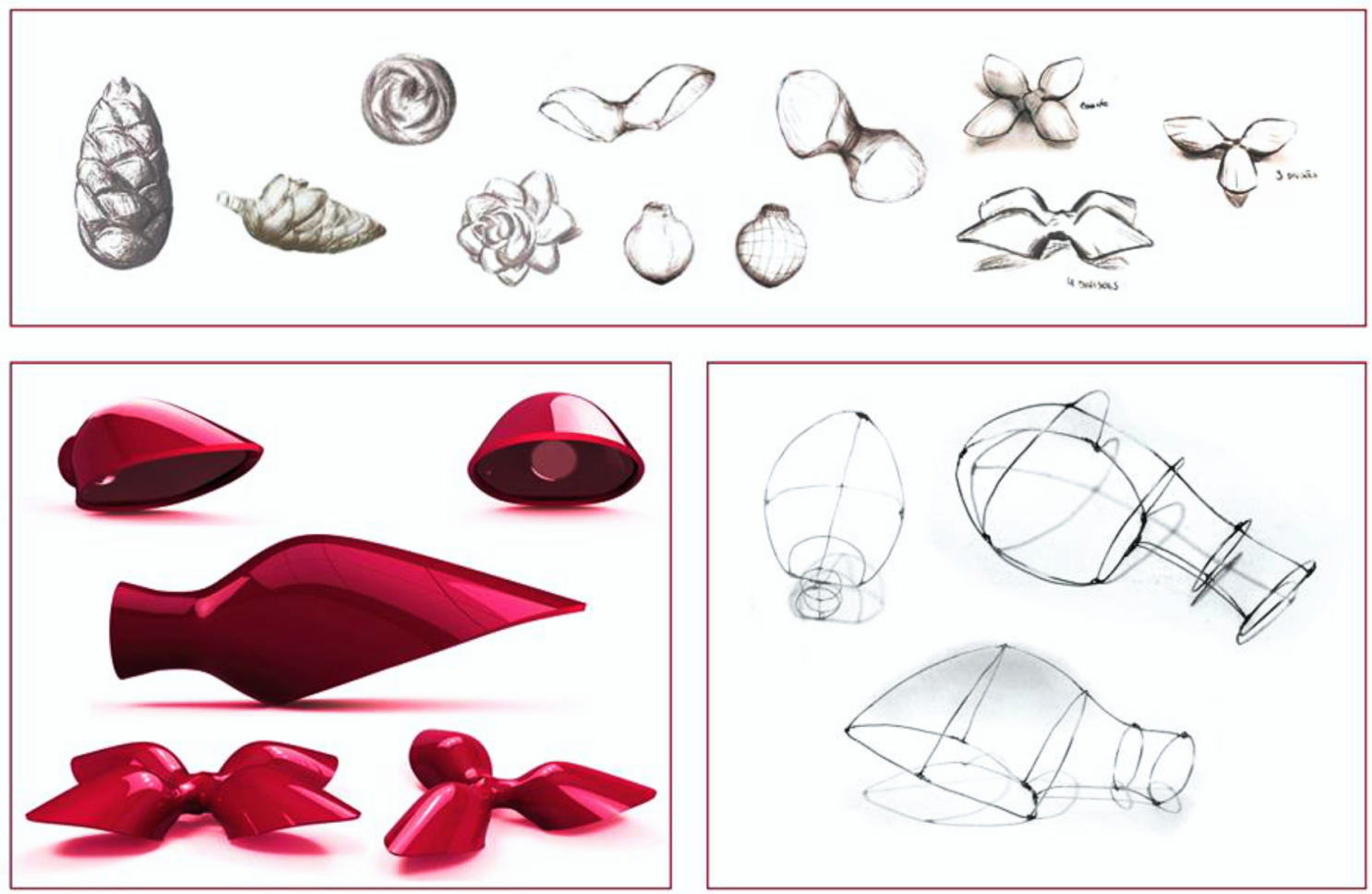

Higor Viana \& Jean Carlo

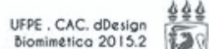
Protessores: Amition Atrudo e Thesto Loilo 
Figura 11.

Banners apresentados em exposição no Centro de Artes de Comunicação da UFPE em 2015, com os trabalhos dos alunos para o encerramento da disciplina de Biomimética. Fonte: SOARES, 2016, p.98.
Na Figura 11 são apresentados outros banners com os trabalhos dos alunos para disciplina ministrada em 2015.2 junto ao Curso de Design da UFPE, através do Laboratório do Biodesign. Este laboratório nasceu em 1998 através do fomento de órgãos como o CNPq e o FACEPE, resultado das pesquisas em Biônica desenvolvidas pelo professor Amilton Arruda no CRIED e no Politécnico de Milão - Itália, em seus estudos de mestrado e doutorado. Atualmente localizado no Centro de Artes e Comunicação da UFPE, ao longo dos anos este laboratório tem aplicado a metodologia de biônica que resultou em diversos trabalhos dentro das disciplinas ministradas para a graduação de Design da instituição, colaborando para disseminar as técnicas de estudo das estruturas naturais referenciais para projetos bioinspirados.

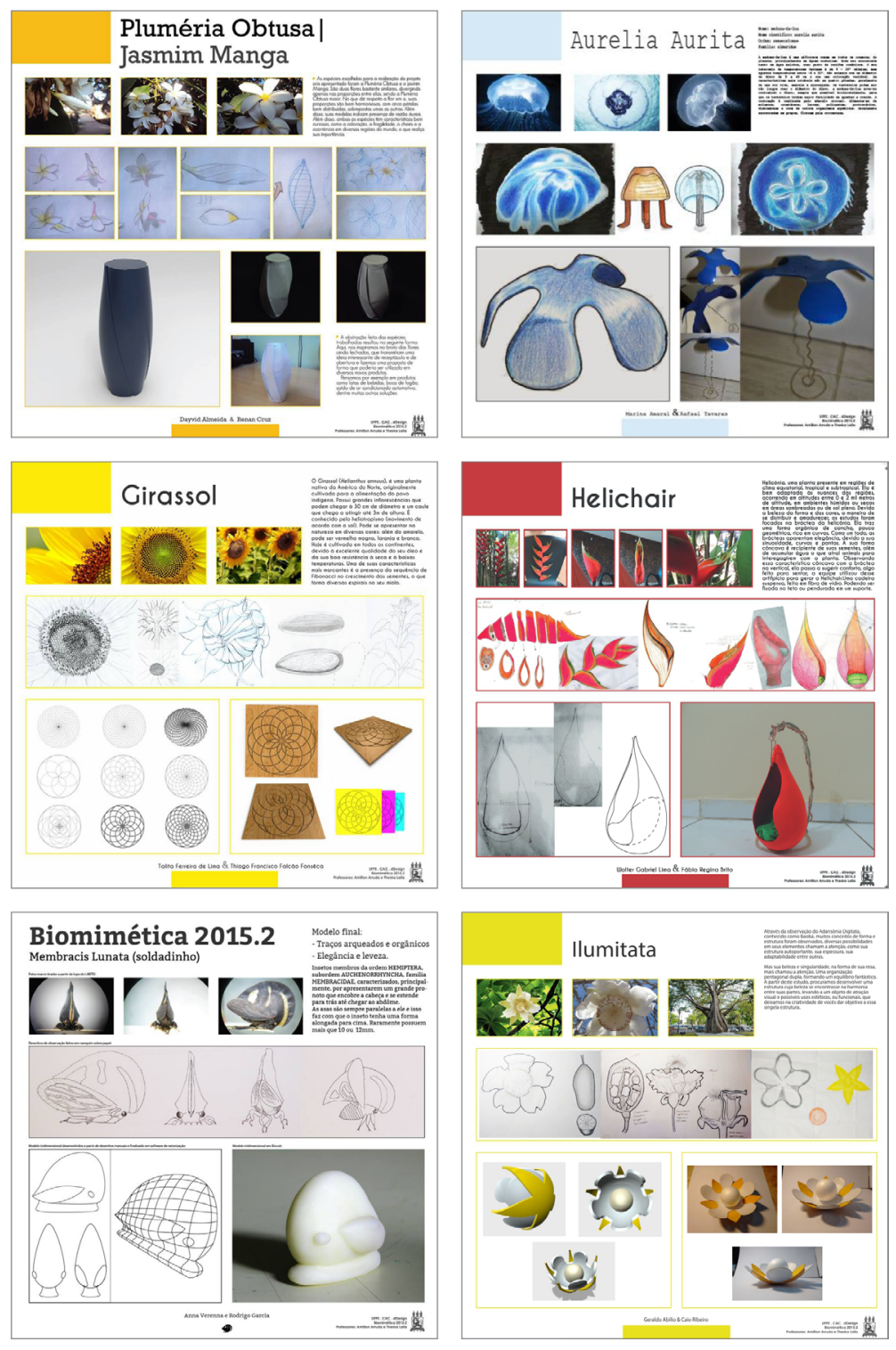


Outro exemplo de projeto bioinspirado também desenvolvido na UFPE é o realizado pelo designer Rodrigo Araújo. Iniciada no mestrado, esta pesquisa foi realizada no laboratório Nexus (UFPE/ BRA), que trabalha na interface entre a sustentabilidade e o design em suas diversas frentes; hoje a pesquisa tem continuidade ao nível de doutorado no laboratório de Biodesign (UFPE/BRA) e FEUP da Universidade do Porto.

Através da união entre o Design paramétrico (Grasshopper), o orgânico (Biomimética) e a fabricação digital (impressão 3D), em parceria com o grupo BI/OS, Araújo (2015) utilizou as estratégias de diferenciação celular da planta Agave, aplicando sua lógica estrutural em escala ampliada de modo a adequá-la no design de estruturas e processos de produção de pranchas de surf (Figura 12). A modelagem paramétrica permitiu que características desta planta, convertidas em parâmetros, pudessem ser aplicadas em incontáveis artefatos que fazem uso de estruturas leves e resistentes, objetivando atingir economia de material e peso, mantendo a leveza. 
Figura 12.

Estudo e aplicação das estratégias do Agave proposta por Rodrigo Araújo com modelo impresso em 3D. Fonte: SOARES, 2016 apud ARAÚJO, 2015, p. 121.

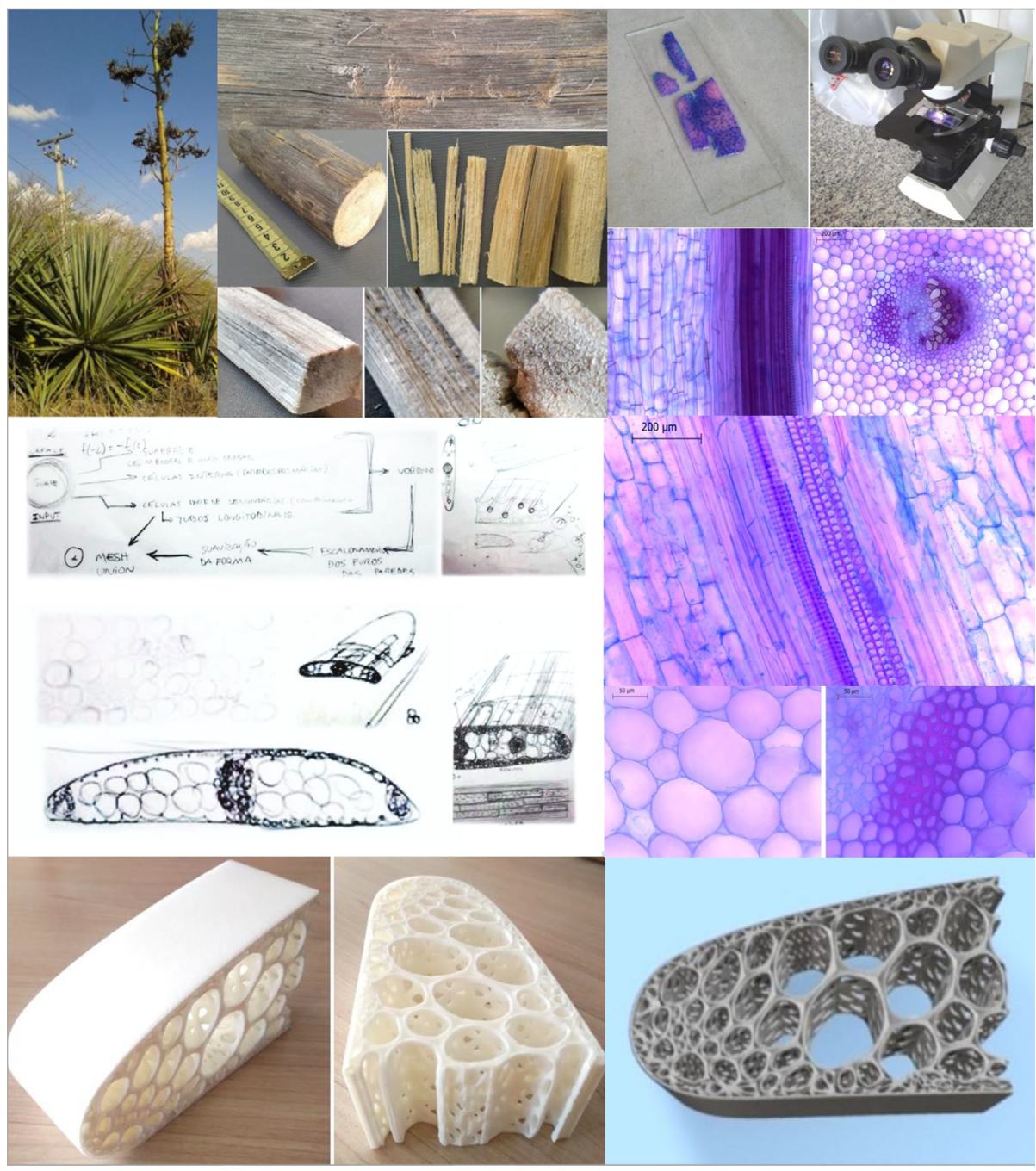

A diferenciação das células maiores e menores foi feita com a lógica das paredes finas para economia de peso e paredes espessadas em pontos de reforço. A aplicação da estrutura bioinspirada final foi feita em uma secção de uma prancha de surf; o estudo constitui um bom exemplo da aplicação da analogia do agave à tecnologia e ao design de artefatos. 


\section{CONSIDERAÇÕES FINAIS}

Dentre as premissas estabelecidas nesse artigo, vale destacar que a mimese no design é compreendida como um método criativo, assim como entende-se a criatividade como um processo cognitivo; portanto, assumimos também que para se entender um artefato é preciso compreender um pouco sobre quem o produz e quem o utiliza e percebe: o usuário e o processo de fruição perceptiva que ocorre dialeticamente entre ambos. Dentre as lacunas desta pesquisa, vale destacar a abrangência do conceito de mimese e suas diversas aplicações, o que dificulta um entendimento homogêneo a respeito do tema e o que gera um maior desafio e deixa a pesquisa mais interessante, pois é preciso fazer uma série de conexões com assuntos correlatos.

Sendo assim, é possível perceber que o objeto mimeticamente projetado e inspirado na natureza, ou simplesmente um objeto bioinspirado, é passível de várias abordagens miméticas, considerando-se os diversos modos de analogia distintos relatados. De fato, o potencial biomimético é tão rico que é possível contemplar as "funções práticas, estéticas e simbólicas do design" (Löbach, 2001), simplesmente através da inspiração na natureza, tal como demonstrado nos exemplos de analogia funcional, morfológica e semântica ou simbólica (Soares, 2016).

É importante considerar que, entre todos os tipos de mimese, 
a biomimética se destaca como abordagem mais complexa, dado todos os modos de analogia com as quais lida. Do ponto de vista morfológico (Soares, 2016) ou estético (Löbach, 2001), as possibilidades de formas, cores e texturas são muito mais orgânicas e diversas, já que os padrões da natureza seguem lógicas que não foram projetadas pelo homem, portanto, muito mais desafiadoras e fora do controle geométrico recorrente no racionalismo formal; o que muitas vezes é suscetível a abstrações da forma para adequação a um propósito específico e uma percepção mais limpa do objeto.

Já na abordagem funcional (Soares, 2016), a natureza é a fonte de inspiração para as estruturas físicas e mecânicas do objeto, o que resulta na solução de problemas relacionados à função prática do design (Löbach, 2001). Por fim, nas analogias simbólicas (Soares, 2016), o grau das abstrações possíveis é mais acentuado, sendo essas, muitas vezes, imperceptíveis na percepção primária do objeto, demandando mediação para que haja a compreensão da analogia.

Para finalizar, em relação à percepção do objeto projetado mimeticamente e inspirado na natureza ou simplesmente bioinspirado, destacamos que, do ponto de vista da estética, é desejável um equilíbrio entre complexidade e abstração, pois a espontaneidade da natureza complementa o racionalismo humano, possibilitando compor o objeto com um grau desejável de heterogeneidade e agradabilidade. 


\section{AGRADECIMENTOS}

Os autores agradecem à PROPG, CAPES e CNPq pela alocação das bolsas aos estudantes envolvidos.

\section{REFERÊNCIAS}

ALENCAR, Eunice M. L. Soriano de.

Criatividade. Brasília: Editora Universidade de Brasília, 1993.

ARAÚJO, Rodrigo. Biomimética e artefatos para ambientes aquáticos: Estratégias de leveza e resistência inspiradas na estrutura celular do Agave. 2015. 115 p. Dissertação (Mestrado) - Universidade Federal de Pernambuco, Recife, Departamento de Design do Centro de Artes de Comunicação.

ARRUDA, Amilton. Bionic Basic: Verso un nuovo modello di ricerca progettuale. 2002. 175 p. Tese (doutorado) - Universidade Politécnico de Milão, Dottorato di Ricerca in Disegno Industriale e Comunicazione Multimediale.

BENYUS, J. M. Biomimética: Inovação inspirada pela natureza. $6^{\text {a }}$ ed. São Paulo: Ed. Pensamento- Cultrix, 1997.

BONSIEPE, G. Diseño industrial. Madrid: Alberto Corazón Editor, 1978.

BOMFIM, Gustavo Amarante. Metodologia para desenvolvimento de projeto. Campina Grande: Editora Gráfica Rodier Ltda, 1984.

BÜRDEK, B. E. História, Teoria e Prática do Design de Produtos. Tradução Freddy Van Camp. São Paulo: Edgard Blücher, 2006.

CRUZ, André J. A. B. Arquitectura [bio]lógica,uma análise da obra de Frei Otto. 2012. 229p. Dissertação de Mestrado Integrado em Arquitectura Faculdade de Ciências e 
Tecnologia da Universidade de Coimbra, Coimbra, Departamento de Arquitectura.

NANAY, Bence. Aesthetics as Philosophy of Perception. New York: Oxford, 2016.

MICHAELIS. Moderno dicionário da língua portuguesa. São Paulo: Melhoramentos. Disponível em: < http://michaelis.uol.com. br/> Acesso em: 11 de março de 2020.

LÖBACH, Bernd. Design Industrial: Bases para a configuração dos produtos industriais; tradução Freddy Van Camp - São Paulo: Blucher, 2001.

PEREIRA, Inês, V.M. Arquitectura Biônica, narrativas de analogias biológicas na Arquitectura. 2013. 171p. Dissertação (Mestrado) - Departamento de Arquitectura, Porto, Faculdade de Arquitectura da Universidade do Porto.

SOARES, Theska Laila de Freitas. A biomimética e a geodésica de Buckminster Fuller: uma estratégia de Biodesign. 2016. 286f. Dissertação (Mestrado em Design) Programa de Pós-graduação em Design, Universidade Federal de Pernambuco, Recife, 2016.

SoUZA, Bruno Carvalho Castro Souza. Criatividade: Uma Arquitetura Cognitiva. Dissertação (Mestrado em Engenharia da Produção). Universidade Federal de Santa Catarina, Florianópolis, 2001.

STEADMAN, Philip. The evolution of designs - biological analogy in architecture and applied art, $1^{\text {a }}$ ed., Cambridge, Cambridge
University Press, 1979, 1988, revised edition, 2008.

THOMPSON, D’arcy Wentworth. On growth

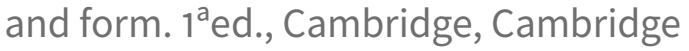
University Press, 1961.

VERSOS, Carlos. A.M. Design biônico: A natureza como inspiração criativa. Dissertação (Mestrado). 2010. 186p - Universidade da Beira Interior, Covilhã, Departamento de engenharia Eletromecânica.

\section{Websites}

Cadeira Vermelha e Azul. Disponível em: <https://pt.wikipedia.org/wiki/Cadeira_ Vermelha_e_Azul> Acesso em: 30/03/2019.

Cadeira Vermelha. Disponível em: <https:// casaclaudia.abril.com.br/blog/design-de-origem/a-poltrona-vermelha-500-metros-de-corda/> Acesso em: 30/03/2019;

Banqueta Tigre. Disponível em: <http://oficinaethos.com.br/colecao/banqueta-tigres/> Acesso em: 30/03/2019. 